\title{
Delays by patients in seeking treatment for acute chest pain: implications for achieving earlier thrombolysis
}

\author{
Andrew D Mumford, Kim V Warr, Sandra J Owen, Alan G Fraser
}

\begin{abstract}
Summary
A study was set up to identify why patients delay seeking medical assistance after myocardial infarction. The study was performed in 100 consecutive patients with suspected acute myocardial infarction admitted to either the University Hospital of Wales, Cardiff, UK, or the Royal Jubilee Hospital, Victoria, British Columbia, Canada (50 patients from each centre). The main outcome measure was the delay from the onset of symptoms to admission to hospital. The mean total delay before admission was 385 minutes (SEM 45). The mean delay incurred by the patient in seeking assistance was 172 minutes (SEM 27), representing $45 \%$ of the total. Delay was longer in patients with crescendo angina and shorter in those later confirmed to have myocardial infarction. Patients with prior ischaemic heart disease $(74 \%$ of patients) presented later than those with no such history. No other demographic or clinical factors predicted early or late presentation.
\end{abstract}

Delays in seeking medical assistance after the onset of severe chest pain contribute significantly to total delays in patients' hospital admission and thrombolysis. The unexpected observation that patients with known ischaemic heart disease delay longer before seeking help in spite of their frequent contact with doctors, suggests that opportunities for educating patients are being wasted. Major efforts are needed to understand and modify behaviour of patients with chest pain to further reduce delays in treatment.

Keywords: chest pain; myocardial infarction; thrombolysis

Department of Cardiology, University of Wales College of Medicine, Heath Park, Cardiff CF4 4XN, UK A D Mumford

K V Warr

S J Owen

A G Fraser

Correspondence to

Dr Alan G Fraser

Accepted 23 June 1998 primary healthcare services. There may then follow the steps of assessment in the commu- nity, transport to hospital, assessment in hospital, and transfer within hospital to the cardiac care unit. Each step increases the total delay before treatment can be given.

Delays in this process have been reduced by initiatives such as rapid-response paramedic ambulances and 'fast-track' admitting systems, ${ }^{34}$ although these measures only reduce delays in medical response after patients with chest pain have decided to seek help. The single largest component of delay to treatment occurs before the patient contacts the medical services. ${ }^{5-14}$ Strategies for reducing total treatment delays must encompass these delays in 'patient decision time' yet little is known about patient behaviour in this critical period.

We therefore undertook a prospective study to identify factors related to variability in patients' decision time. This was performed in two geographically distinct centres, to compare different populations and to test the general applicability of our findings. By recording demographic variables and obtaining detailed accounts of patients' clinical histories, including previous experience of chest pain, we attempted to characterise patients who presented early and late, and thereby to design possible strategies for reducing delay.

\section{Patients and methods}

The study was performed simultaneously in two centres. At the University Hospital of Wales in Cardiff, patients with suspected myocardial infarction arrived for assessment in an Emergency Admissions Unit either after contacting the emergency ambulance service directly or by first presenting to a general practitioner or to the Accident and Emergency department in a nearby hospital. At the Royal Jubilee Hospital, Victoria, British Columbia, Canada, patients presented directly to the Emergency Admissions unit or were referred by a cardiologist or family doctor. In both hospitals, after assessment in the Emergency Admissions ward, those with suspected acute myocardial infarction were transferred directly to a dedicated cardiac care unit.

The study was continued for about 8 weeks until 50 consecutive patients from each centre had been included. Eligible patients had presented with a history compatible with acute myocardial infarction and were admitted to the cardiac care unit. Chest pain was not a 
prerequisite for inclusion, but only patients who developed symptoms outside hospital were eligible. Five Canadian and seven British patients were excluded because of unwillingness or inability to participate.

On admission, a record sheet for each patient was completed by the cardiac care unit nurses. With information obtained from the patients or their relatives and from nursing and ambulance records, we established the timings of events leading to admission. The following intervals were calculated:

- patient decision time: from the onset of acute symptoms to the decision to seek medical assistance

- first consultation time: the time awaiting initial contact and assessment by the primary healthcare services

- transport time: from leaving the place of first consultation to arrival at hospital

- hospital assessment time: from arrival in hospital to admission to the cardiac care unit

- total delay time: from the onset of symptoms to the patient's arrival on the cardiac care unit.

When British patients presented directly to the Accident and Emergency department, time spent awaiting and undergoing assessment by casualty staff was recorded as the 'first consultation time'. When patients at either hospital presented as a self-referral to the Emergency Admissions unit, the first consultation time was not recorded.

Within 48 hours of admission, patients were asked to complete a standard questionnaire to assess further details of the circumstances surrounding their admission. This was reviewed with each patient prior to their discharge to ensure correct completion. The questions were of open-ended format and assessed factors thought to influence delay by patients in reporting their symptoms. In addition to the patients' demographic details, the circumstances of the onset of symptoms, their nature, and patients' interpretations were recorded. The perceived severity of pain was assessed with a visual analogue scale (graded $0-10$, with 10 representing the most severe pain ever). The questionnaire examined the patient's behaviour and that of attending relatives and friends, from the onset of symptoms up to the decision to seek medical assistance. Pre-existing diagnoses of ischaemic heart disease were recorded, and history of previous angina was assessed using the Rose questionnaire. ${ }^{15}$

Statistical analysis was performed using minitab, on the whole group and on a modified group excluding patients who presented longer than 24 hours after the onset of symptoms. This excluded patients whose hospital admission was prompted by complications arising from recent myocardial infarction, rather than the infarction itself. Data are quoted either as mean values with standard errors or median values with quartile ranges. Statistical significance was set at 0.05 for two-tailed tests. Data were compared using chi-squared and Student's $t$-tests as appropriate.

\section{Results}

STUDY POPULATIONS

A total of 100 patients were studied, 50 from each centre. Their mean age was 64 years (range 37-87 years), and 65 were men. The two cohorts are compared in table 1. There were no significant differences between the demographic characteristics of the study groups.

PREVIOUS EXPERIENCE OF ISCHAEMIC HEART

DISEASE

The subjects had considerable previous experience of ischaemic heart disease, both personally and through friends or relatives (table 2). In total, 73 had a prior history compatible with angina, although in 12 patients from each centre this had not been diagnosed by a doctor, while 35 patients had had chest pain for the first time in the year before admission, including 11 with symptoms only in the previous month. There was an increase in the frequency of chest pain immediately prior to admission, with 24 British and 27 Canadian patients describing crescendo angina in the 48 hours before presentation.

Twenty-six British and 30 Canadian patients were confident that they knew the symptoms of a 'heart attack' although when asked to indicate as many symptoms as they knew or to guess if they were unsure, 45 British and 47 Canadian patients correctly stated at least one symptom (table 3).

Table 1 Demographic features of study groups showing mean ages and age ranges in years, and numbers of patients according to sex, socioeconomic group, marital status, educational attainment and distance of residence from hospital

\begin{tabular}{lll}
\hline & $\begin{array}{l}\text { University } \\
\text { Hospital of } \\
\text { Wales } \\
(n=50)\end{array}$ & $\begin{array}{l}\text { Royal } \\
\text { fubilee } \\
\text { Hospital } \\
(n=50)\end{array}$ \\
\hline Age (years) & $63(37-87)$ & $65(42-87)$ \\
Sex (male) & 33 & 32 \\
Socio-economic group (1-3n) & 25 & 31 \\
Married & 40 & 29 \\
Higher education & 6 & 16 \\
Living within 5 miles of hospital & 34 & 34 \\
\hline
\end{tabular}

^Reference 16

Table 2 Numbers of patients with previous experience of ischaemic heart disease

\begin{tabular}{lll}
\hline & $\begin{array}{l}\text { University } \\
\text { Hospital of } \\
\text { Wales } \\
(n=50)\end{array}$ & $\begin{array}{l}\text { Royal } \\
\text { fubilee } \\
\text { Hospital } \\
(n=50)\end{array}$ \\
\hline $\begin{array}{l}\text { Previous myocardial infarction } \\
\begin{array}{l}\text { Previous diagnosis of angina } \\
\text { History compatible with prior }\end{array}\end{array}$ & 22 & 18 \\
$\quad$ angina & 21 & 28 \\
$\begin{array}{l}\text { Previous chest pain longer than } \\
\quad \text { 20 mins }\end{array}$ & 33 & 40 \\
$\begin{array}{l}\text { Previous rest pain } \\
\text { Previous prescription for nitrate }\end{array}$ & 16 & 14 \\
Previous medical advice about IHD & 17 & 21 \\
Family member has IHD & 25 & 23 \\
Friend or colleague at work has IHD & 33 & 24 \\
\hline
\end{tabular}

$\star$ Positive reply to the Rose Questionnaire..$^{15}$ IHD $=$ ischaemic heart disease 
Table 3 Numbers of patients suggesting symptoms of myocardial infarction

\begin{tabular}{lll}
\hline & $\begin{array}{l}\text { University } \\
\text { Hospital of } \\
\text { Wales }(n=50)\end{array}$ & $\begin{array}{l}\text { Royal fubilee } \\
\text { Hospital } \\
(n=50)\end{array}$ \\
\hline Chest pain & 34 & 41 \\
Arm pain & 16 & 20 \\
Jaw pain & 4 & 8 \\
Shortness of breath & 3 & 16 \\
Nausea and sweating & 6 & 14 \\
\hline
\end{tabular}

Canadian patients cited breathlessness as a symptom of a 'heart attack' more often than British patients $(p<0.01)$ but otherwise there were no significant differences in medical history or symptomatic knowledge between the study groups.

\section{NATURE OF PRESENTING SYMPTOMS}

The presenting symptom was chest pain in 92 subjects. This was perceived as severe ( $>8$ on visual analogue scale) by 26 British and 20 Canadian patients. Additional symptoms listed by patients were sweating ( 52 patients), breathlessness (45), weakness or collapse (25) and nausea (21). When their symptoms started, 34 British and 38 Canadian patients correctly attributed their presenting complaint to the heart. Otherwise patients blamed the gastrointestinal tract (10 patients), the musculoskeletal system (three), the lungs (four), or were unsure (11).

\section{DIAGNOSIS}

The ultimate diagnoses in the British patients were myocardial infarction in 35 cases and angina pectoris in 15 . In the Canadian patients, myocardial infarction was diagnosed in 12, angina pectoris in 31 and non-cardiac chest pain in seven $(\mathrm{p}<0.05)$. All patients with myocardial infarction were given thrombolysis, apart from eight British and four Canadian patients who had a contraindication. Two patients with angina received thrombolysis.

TREATMENT DELAYS

The mean (SD) total delay from the onset of symptoms to hospital admission in the combined cohort of 100 patients was 385 (45) minutes. A mean (SD) delay of 172 (27) minutes occurred whilst patients decided to seek medical assistance, representing $45 \%$ of the

Table 4 Median times in minutes, with quartile ranges in parentheses for total delay to admission and the constituent delays in patient decision, first consultation, transport, and hospital assessment (reported separately for patients who did not, or did, receive thrombolysis)

\begin{tabular}{lll}
\hline & $\begin{array}{l}\text { University Hospital of Wales } \\
(n=50)\end{array}$ & $\begin{array}{l}\text { Royal fubilee Hospital } \\
(n=50)\end{array}$ \\
\hline $\begin{array}{l}\text { Patient decision time } \\
\text { First consultation time }\end{array}$ & $98(20-222)$ & $104(28-194)$ \\
$\begin{array}{l}\text { Transport time } \\
\text { Hospital assessment time }\end{array} \quad 40(20-60)$ & $19(5-30)$ \\
$\quad \begin{array}{l}\text { No thrombolysis }(n=13) \\
\begin{array}{l}\text { Thrombolysis }(n=37) \\
\text { Total delay }\end{array}\end{array}$ & $13(7-27)$ & $19(8-31)$ \\
& $68(35-140)$ & $65(30-106)$ \\
\hline
\end{tabular}

Patient characteristics with no demonstrable association with 'patient decision delay'

- demographic details

- age and sex

- socio-economic group

- marital status

- educational level

- distance living from hospital

- previous knowledge of ischaemic heart disease

- previously sought advice about chest pain

- family history of ischaemic heart disease

- social contact with ischaemic heart disease

- awareness of symptoms of ischaemic heart disease

- correct identification of the symptoms of myocardial infarction

- circumstances of admission

- time or place of onset

- spouse, friends or relatives present

- patient vs spouse, friends, or relative seeking assistance

- principal symptom

- interpretation of symptoms

- number of associated symptoms

- perceived severity of symptoms

- general practitioner or A\&E consultation vs self-referral

- method of transport to hospital

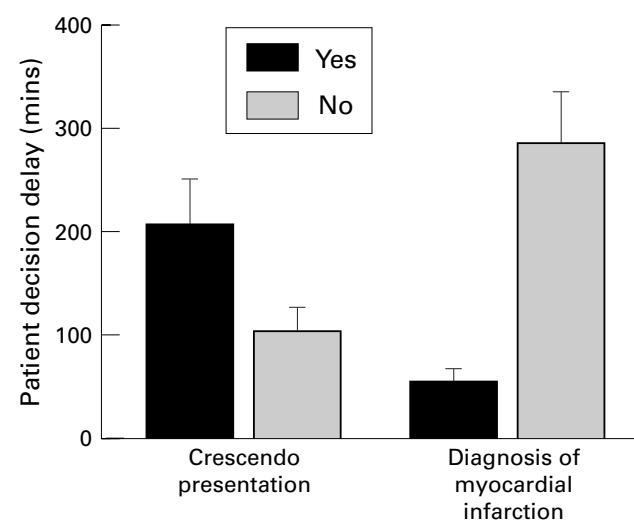

Figure 1 Mean 'patient decision delay' in patients presenting in less than 24 hours $(n=87)$ according to the presence of crescendo symptoms and an ultimate diagnosis of myocardial infarction

total delay. The other mean (SD) contributions to total admission delay were first consultation time (65 (18) minutes; 17\%), transport time (20 (2) minutes; 5\%) and hospital assessment time (129 (15) minutes; 33\%).

Sixty patients presented within 2 hours of the onset of their symptoms and eight Canadian and five British patients were admitted to hospital more than 24 hours afterwards. Even when these late presenting patients were excluded, the distribution of patient decision delays remained skewed, with a substantial proportion of patients presenting between 2 and 24 hours after their symptoms developed. Table 4 shows the median delays when patients admitted with symptoms which had lasted for more than 24 hours were excluded. There were no significant differences between the British 


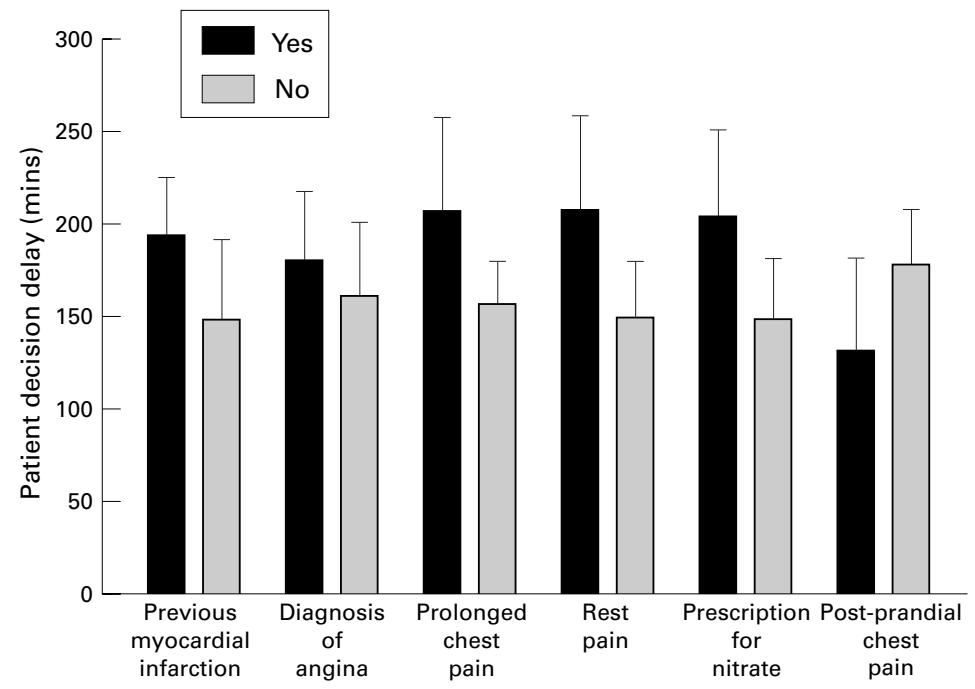

Figure 2 Mean 'patient decision delay' in patients presenting in less than 24 hours $(n=87)$ according to previous experience of ischaemic heart disease

and Canadian groups in any of the recorded delay times.

There was no relationship between 'patient decision delay' and many factors determined from the questionnaire (box), but two factors were associated with prolonged delay in both study groups. Patients with crescendo symptoms presented later than patients with abrupt onset of symptoms $(\mathrm{p}<0.05)$, and patients with a subsequent diagnosis of angina or noncardiac chest pain presented later than those with myocardial infarction $(\mathrm{p}<0.05)$ (figure 1$)$.

There was a consistent relationship between patients' previous experience of ischaemic heart disease and patient decision delay, although it was not statistically significant (figure 2). Patients who had a prior history of angina or myocardial infarction tended to present later than those with no such history. The only exception was in patients with prior post-prandial chest pain who tended to present earlier. There was no relationship between patient decision delay and the existence of a family member or friend with ischaemic heart disease.

\section{Discussion}

DELAYS BEFORE ADMISSION

In this study, patients sought medical help with a mean delay of 172 minutes after developing chest pain. This accounted for almost half of the total delay before admission to the cardiac care unit. In the whole group, the mean patient decision delay was greatly prolonged by a minority of patients who presented particularly late. Even when such patients were excluded, however, delays remained unsatisfactory. Comparable data have been reported from North America and Europe both before ${ }^{5-11}$ and after ${ }^{12-14}$ the introduction of thrombolytic therapy into clinical practice.

In comparison to delays made by patients, the delays attributable to assessment by medical personnel and transport are modest, and with few exceptions, showed little variation between patients. Those patients who were subsequently thrombolysed were assessed more rapidly after arriving in hospital. Presumably the need for urgent thrombolysis was identified quickly and these patients were then given priority.

FACTORS ASSOCIATED WITH EARLY AND LATE PRESENTATION

The only clinical feature associated with earlier presentation was that patients with myocardial infarction sought help faster than those with angina or non-cardiac chest pain. This is difficult to explain because these patients had no pre-knowledge of their diagnosis and their symptoms were no more severe or diverse than patients without myocardial infarction. Shorter patient decision delay in subjects with myocardial infarction may have been promoted by phenomena such as angor animi, which are often recorded in descriptions of myocardial infarction but were not specifically addressed in this study.

Late presentation was more common in patients with crescendo angina, suggesting that when symptoms developed gradually, patients failed to appreciate their importance and that more significance was attributed to chest pain of sudden onset even if of equal intensity. Other studies also found that the rate of change of symptoms dictated the speed with which assistance was sought. ${ }^{710}$

\section{THE INFLUENCE OF PREVIOUS ISCHAEMIC HEART} DISEASE

In general, patients had extensive experience of ischaemic heart disease, either in themselves or in associates, although in many cases the patients had not received a formal diagnosis of angina despite seeking medical advice. These data reflect difficulties in the out-patient diagnosis of angina and suggest that general practitioners and others may not be fully utilising opportunities to investigate, advise, and educate patients with chest pain.

There was a consistent trend in our study for patients with previous diagnoses of angina or myocardial infarction to present later than those with no such history. We expected such patients to have had frequent contact with the medical services and therefore to have been educated in the importance of early presentation. This paradoxical result has been demonstrated in previous studies where delay was increased after previous angina ${ }^{710}$ and preexisting diabetes mellitus, hypertension, or cardiac failure. ${ }^{12}$ One group reported that delay was reduced in patients who had previously been admitted to a cardiac ward or who had recently consulted a physician, ${ }^{8}$ although the same group reported later that recent consultation was associated with prolonged delay. ${ }^{11}$

We were unable to identify any other factors that were associated with prolonged patient decision delay and this finding is consistent with previous studies which have also found it difficult to predict which patients with chest pain present late. From a total of 2207 patients examined, ${ }^{5-14}$ there have been only sporadic 
associations between delay and demographic characteristics or symptoms. Prolonged delay has been reported in the elderly and in women $^{612}$ and in patients of lower socioeconomic status. ${ }^{11}$ The perception of symptoms as severe ${ }^{5}$ and conviction by the patient that symptoms derived from the heart, have been associated with reduced delay. ${ }^{511}$ These findings are inconsistent, and are not supported by our data. A common problem encountered in our own, and previous studies is that very subtle variations in patient behaviour may be difficult to differentiate with comparatively small study sizes. It is reasonable to conclude, however, that simple demographic characteristics do not allow the prior identification of patients on an individual basis who are at particular risk of late presentation.

THE PROCESS OF SEEKING ASSISTANCE

The observation that delays in admission are not associated with demographic characteristics or the nature of symptoms, indicates that delay may relate to more complex patient characteristics such as personality and individual interpretation of symptoms. The processes involved in decisions to seek help involve multiple perceptive and cognitive steps, ${ }^{6}$ each of which may be influenced by many interacting personal and external factors.

Patients must recognise their symptoms as representing an important deviation from normal, and therefore they must have an accurate knowledge of the symptoms of myocardial infarction. In our study most patients were able to cite chest pain as the predominant symptom but many still had misconceptions about its interpretation. For example, some patients knew the symptoms yet presented late with chest pain themselves, because they believed that myocardial infarction only occurred during physical exertion or was always accompanied by dyspnoea.

Impaired recognition of the significance of symptoms may also result from denial. This phenomenon is a normal psychological defence mechanism whereby patients allay anxiety by repudiating the whole or part of their symptoms. It is common in patients with ischaemic heart disease ${ }^{17}$ and frequently takes the form of displacement of the perceived origin of acute symptoms onto an alternative source, particularly one from which symptoms have previously been overcome with ease. This leads to delay in seeking assistance until denial is overwhelmed by the persistence or progression of symptoms. There is evidence for this phenomenon in our study since, although our patients had a good general knowledge of the features of myocardial infarction, they frequently attributed the same symptoms in themselves to a non-cardiac source. It is difficult to explain their initial misconceptions without invoking denial.

After patients successfully recognise the severity of their symptoms, they must also realise that they warrant urgent medical assistance. Patients may prolong this step by engaging in unnecessary non-therapeutic activity. ${ }^{7}$ In our study patients were often reluctant to abandon their social obligations and some made elabo- rate preparations for an anticipated stay in hospital. Activities included changing clothes and packing an overnight bag or contacting relatives before calling an emergency ambulance. Patients may also delay or refuse admission because they cannot tolerate abandoning their usual activities or adopting the sick role. ${ }^{6}$

The behaviour of those patients who had previous heart disease highlights the complexity of the process of calling for medical assistance. The perception of symptoms in this group may have been masked by pre-existing anti-anginal treatment, and impending myocardial infarction often differs from chronic stable angina only in the severity of chest pain. Patients already accustomed to this may not have identified severe pain as unusual, particularly when symptoms developed slowly as in crescendo presentations. Patients with chronic angina frequently prevaricated by making prolonged attempts to relieve their symptoms with sublingual nitrate. Anxiety generated by the possibility of repeating previous unpleasant admissions may have provoked denial phenomena. We need constantly to reinforce the message to patients with angina that admission is never inappropriate if they have severe symptoms.

\section{PUBLIC EDUCATION}

Efforts to incorporate psychological factors in patients' perception of symptoms has been assessed in Swedish and Canadian trials utilising mass-media education campaigns to emphasise the importance of early presentation after chest pain. ${ }^{18} 19$ This strategy significantly reduced delays in presentation, at the expense of a greatly increased rate of presentation of patients with non-cardiac diagnoses. The benefits of public education are clear in those patients who delay admission due to misconceptions about the significance of their symptoms or the need to seek medical assistance. The advantages are less clear in patients who delay admission through the processes of denial. This aspect of patients' behaviour is resistant to education and may even be exacerbated by giving more information. ${ }^{8}$ More understanding of these phenomena is needed, and it is likely that the difficult task of modifying behaviour cannot be accomplished by mass-media campaigns alone.

CLINICAL IMPLICATIONS

The logical way to reduce overall delays in admitting patients to the cardiac care unit would be to reduce its largest single component: the time taken by the patient to seek medical assistance after developing symptoms. Many patients still incur unacceptable delays because they are slow to present, but behaviour at this time is highly variable. The unexpected finding that patients with previous ischaemic heart disease, who were the majority of patients with myocardial infarction, actually presented later, is an indictment of our present services. The reasons for this apparently paradoxical result are complex and multifactorial, but more specific education of patients and development 
of methods to modify behaviour are urgently needed.

Doctors and nurses should give simple and unambiguous advice to all patients with any evidence of ischaemic heart disease, and to their relatives: emergency medical assistance should be sought in the event of any severe central chest pain which lasts longer than 15 minutes, or any pain that does not respond to

1 Gruppo Italiano per lo Studio della Streptochinasi nell'Infarto Miocardico (GISSI). Effectiveness of intravenous thrombolytic treatment in acute myocardial infarction. Lancet 1986;1:397-401.

2 ISIS-2 Collaborative Group. Randomised trial of intravenous streptokinase, oral aspirin, both, or neither among 17187 cases of suspected acute myocardial infarction. Lancet 1988;2:348-60.

3 Kereiakes DJ, Gibler WB, Martin LH, Pieper KS, Anderson LC. Relative importance of emergency medical system transport and the prehospital electrocardiogram on reductransport and the prehospital electrocardiogram on reducing hospital time delay to therapy for acute myocardia infarction: a preliminary report from

4 Pell ACH, Miller HC, Robertson CE, Fox KAA. Effect of 'fast track' admission for acute myocardial infarction on 'fast track' admission for acute myocardial

5 Hackett TP, Cassem NH. Factors contributing to delay in responding to the signs and symptoms of acute myocardial infarction. Am $\mathcal{F}$ Cardiol 1969;24:651-8.

6 Moss AJ, Wynar B, Goldstein S. Delay in hospitalization during the acute coronary period. Am f Cardiol 1969;24: 659-65.

7 Simon AB, Feinleib M, Thompson HK. Components of delay in the pre-hospital phase of acute myocardial infarction. Am f Cardiol 1972;30:476-82.

8 Erhardt LR, Sjogren A, Sawe U, Theorell T. Prehospital phase of patients admitted to a coronary care unit. Acta Med Scand 1974;195:41-6.

9 Gillum RF, Feinleib M, Margolis JR, Fabsitz RR, Brasch RC. Delay in the prehospital phase of acute myocardial infarction. Arch Intern Med 1976;136:649-54. sublingual nitrates. Existing patients are the most important target group for this advice, but opportunities for education afforded by their frequent contact with the medical services are currently being wasted.

We would like to thank Dr Richard Mildenberger, Royal Jubilee Hospital, Victoria, British Columbia for his assistance with the recruitment of the Canadian cohort of patients.

10 Schroeder JS, Lamb IH, Hu M. The prehospital course of patients with chest pain. Am f Med 1978;64:742-8.

11 Sjogren A, Erhart LR, Theorell T. Circumstances around the onset of myocardial infarction. A study of factors relevant to the perception of symptoms and to the delay in arriving at a coronary care unit. Acta Med Scand 1979;205: arriving

12 Turi ZG, Stone PH, Muller JE, et al. Implications for acute intervention related to time of hospital arrival in acute myocardial infarction. Am f Cardiol 1986;58:203-9.

13 Rawles JM, Haites N. Patient delay in acute myocardial infarction. Br Heart f 1987;59:112.

14 Leitch JW, Birbara T. Freedman B, Wilcox 1, Harris PJ. Factors influencing the time from onset of chest pain to arrival at hospital. Med 7 Aust 1989;150:6-10.

15 Rose GA, Blackbum H, Gillum RF, Prineas RJ. Cardiovascular survey methods. WHO monograph series, no 56 Geneva: World Health Organisation, 1982.

16 Office of Population Censuses and Surveys. Classification of occupation and coding index. London: Her Majesty's Stationary Office, 1980

17 Olin HS, Hackett TP. The denial of chest pain in 32 patients with acute myocardial infarction. $7 A M A 1964 ; 190$ : $977-81$

18 Herlitz J, Hartford M, Blohm M, et al. Effect of a media campaign on delay times and ambulance use in suspected acute myocardial infarction. Am f Cardiol 1989;64:90-3.

19 Mitic VM, Perkins RRT. The effect of a media campaign on heart attack delay and decision times. Can f Public Health $1984 ; 75: 414-8$.

\section{Medical Anniversary}

\section{Charles Herbert Best, 27 February 1899}

Charles Herbert Best (1889-1978) was born of Canadian parents in Maine, USA, where his father was a physician. He was educated at Toronto University, where he qualified MD (1925) and where he met Frederick Grant Banting, his co-discoverer of insulin. On 11 January 1922, the first insulin was given successfully to a 14 -year-old diabetic at the Toronto General Hospital. In 1923, the Charles H Best Institute, Toronto, built in his honour, was opened by Sir Henry Dale. 'Charley', as he was universally known, died on 30 March 1978 in Toronto. - DG fames 